\title{
Creative commons no governo federal brasileiro: Comunicação e democratização ${ }^{1}$
}

\section{Creative commons in the Brazilian federal government: Communication and democratization}

\author{
Gabriella da Costa \\ Universidade de Brasília (Brasil) \\ gabrielladacosta@gmail.com
}

Recibido: 30 de julio de 2013

Aceptado y Publicado: 2 de octubre de 2013

\section{Resumen}

O artigo pretende verificar a existência da licença Creative Commons no Governo Federal Brasileiro, a partir da ánalise dos sites e portais dos ministérios do Governo, analisando se estes possuem algum tipo de selo de compartilhamento. Além de realizar um apanhado histórico do de Creative Commons e das discussões sobre o direito autoral nos últimos anos.

O Creative Commons é uma Organização não governamental e internacional que visa expandir a quantidade de obras disponíveis, através de suas licenças que permitem a cópia e compartilhamento do direito autoral. A organização criou diferentes tipos de licenças de direitos autorais. As licenças permitem o controle sobre a maneira como a propriedade intelectual será compartilhada permitindo a padronização de declarações de vontade de compartilhar, licenciar e distribuir conteúdos como: textos, músicas, imagens, filmes, artigos dentre outros. Permitindo então, que detentores de conteúdos possam abrir mão em favor do compartilhamento dos seus direitos, tendo um modelo de licenças.

Para tanto, o presente artigo pretende analisar o uso da licença Creative Commons nos portais dos vinte e cinco ministérios e nove secretarias do Governo Federal Brasileiro. Entendendo que o uso da licença permite a democratização da comunicação e o acesso a informação por meio do compartilhamento e uso dos arquivos e publicações do governo em

\footnotetext{
1 Artículo producto de una Ponencia presentada en el VI Encuentro Panamericano de Comunicación COM PANAM 2013 celebrado la Escuela de Ciencias de la Información de la Universidad Nacional de Córdoba (Argentina), durante los días 5, 6 y 7 de junio de 2013.
} 
prol da sociedade. Além de representar um avanço histórico nas leis que dizem respeito ao direito autoral.

No ano de 2011, a então Ministra de Cultura do Estado retirou o selo Creative Commons do site do portal do ministerio. Por isso, além de realizar a análise dos portais faz-se necessário realizar um apanhado histórico das ações do Governo Federal Brasileiro em relação as questões do direito autoral.

\section{Abstract}

The article intends to verify the existence of the Creative Commons license in the Brazilian Federal Government, from the analysis of the sites and portals of government ministries, analyzing whether they have some sort of seal of sharing. In addition to conduct a historical overview of the Creative Commons and discussions about copyright in recent years.

The Creative Commons is a non-governmental organization and international levels aimed at expanding the number of works available through its licenses that allow copying and sharing of copyright. The organization has created different types of copyright licenses. The licenses allow control over how intellectual property will be shared allowing the standardization of declarations of willingness to share, license and distribute content such as text, music, pictures, movies, among other items. Allowing then that content owners may give up in favor of sharing their rights, having a license model.

Therefore, this article aims to analyze the use of Creative Commons license in the portals of the twenty five nine ministries and departments of the Brazilian Federal Government. Understanding the use of license allows the democratization of communication and access to information through the sharing and use of archives and government publications on behalf of society. Besides representing a historic breakthrough in the laws pertaining to copyright.

In 2011, the then Minister of Culture of the State withdrew the Creative Commons seal the portal site of the ministry. Therefore, in addition to performing analysis of portals it is necessary to perform a historical overview of the actions of the Brazilian Federal Government regarding the issues of copyright.

Palavras chave: Licenças; Creative Commons; Governo Federal; Compartilhamento; Direito Autoral; Democratização do acesso. 
Keywords: Licenses, Creative Commons, Federal Government; sharing; copyright; Democratizing access

\section{1. Introdução}

Gritar, conversar, reverberar, produzir, reproduzir, comunicar. Uma das necessidades mais latentes de nossa sociedade, o fluxo de informações que as pessoas hoje estão sujeitas é enorme.

A liberação do polo emissor proporcionada pela internet pôs na mão de qualquer cidadão conectado a rede o poder de produção de informação, de conteúdo. Não só produção como compartilhamento destes, uma espécie de reação em cadeia de compatilhamentos.

Logo, para tanto, a informação deve ser tratada não como um bem privado, mas sim como um elemento de utilidade pública. O conteúdo produzido não precisa estar ligado unicamente ao emissor que o produziu. Ele deve ser difundido, divulgado, e modificado sujeito ao uso comum, é claro que dando os devidos créditos e agradecimentos para aquele que o fez, que o gerou, como forma de reconhecimento.

Ao dissertamos sobre todo esse panorama, em especifico o da produção de conteúdo noticioso, temos como objetivo estabelecer uma ponte entre o direito autoral e o direito de livre uso. Dilema esse que $\mathrm{O}$ Creative Commons (CC). Uma organização sem fins lucrativos que criou licenças autorais que mostram até onde uma obra ou conteúdo pode ser compartilhado, alterado ou vendido.

A partir do seu surgimento, seu sucesso foi notável. Uma medida promovida por eles facilitando a difusão de conteúdo de forma organizada e justa, sem ferir os direitos que o produtor exige. Analisando tal iniciativa do viés da comunicação, esta pode ser vista como uma ação democratizante, que ajuda não só na divulgação de conteúdos como também na inclusão dos indivíduos no processo criativo.

Por ser uma medida que visa a democratização do conteúdo, pretende-se analisar no decorrer deste ensaio, como os ministérios do governo federal brasileiro encararam a idéia difundida pelo CC com relação a colocar em seus seus sites - que servem como porta de escoamento de atividades realizadas pelo ministério e fonte de noticias para população do país - as licenças que permitem o uso e compartilhamento do conteúdo por aqueles que o acessam. 


\section{Direito autoral}

As discussões sobre o direito autoral aplicado a internet perpassam por vários campos do conhecimento que ultrapassam o campo do Direito. Mesmo sendo uma viga fundamental nas relações construídas na internet, a comunicação não tem sido a principal área a tratar de temas referentes aos direitos autorais na rede, pois esta discussão ainda está presa a questões jurídicas.

As dicotomias entre o compartilhamento de conteúdos, informações e conhecimento na internet $e$ as leis que regem os direitos autorais passam pela academia, nos estudos sobre 0 assunto, na ampla liberação de estudos científicos, ou ainda, no mercado, seja na área fonográfica, cinematográfica, editorial ou no uso de patentes. Além de ser discutida pela sociedade, por meio de ativistas da liberdade na internet, por produtores de conteúdos que querem seus direitos reservados e por organizações que buscam regular o compartilhamento na rede, como é o caso da organização Creative Commons.

Com a ascensão do uso da internet os indivíduos passaram a ser protagonistas de um novo meio de comunicação, passam a ser considerados emissores. O ser humano passa a encontrar mais uma identidade como individuo, ele se torna também internauta. $E$ como internauta ele pode produzir, reproduzir e compartilhar conteúdos. O compartilhamento se tornou irreversível; foram surgindo mecanismos para compartilhar cada vez mais. Na internet as pessoas passaram a se unir por compatibilidade de ideias, gêneros e estilos, criando de redes na internet. No caso da música, artistas passaram a não depender mais dos agentes intermediários como gravadoras, criando uma relação direta com o seu usuário, sem necessitar mais das intermediações da indústria fonográfica. Casteells afirma que uma das principais características da sociedade em rede é justamente a capacidade de as pessoas apropriarem-se criativamente dos novos meios.

"As novas tecnologias da informação não são simplesmente ferramentas a serem aplicadas, mas processos a serem desenvolvidos. Usuários e criadores podem tornar-se a mesma coisa. Dessa forma, os usuários podem assumir o controle da tecnologia como no caso da Internet". (CASTEELS,1999, p.51)

O poder da internet gerou o desafio de como entender o que é compartilhado na rede. Tendo em vista que as leis autorais que antes se aplicavam conteúdos materiais - fora da rede agora também se aplicam aos conteúdos dentro dela e são controlados a partir da propriedade. Ocorre então uma tentativa de trazer para o ambiente das redes digitais - onde 
se transferem bens intangíveis - o mesmo sistema de propriedade de bens materiais Escassos e marcados pelo desgaste, parece estar enfrentando inúmeros problemas de difícil solução. (Amadeu, p. 06)

As leis de direitos autorais são bem rigorosas no que diz respeito aos direitos dos detentores de conteúdos. O direito autoral tem por premissa ter todos os direitos reservados e privilegiar o autor. "No sistema jurídico da propriedade intelectual adotado no Brasil, até mesmo os rabiscos feitos em um guardanapo já nascem com 'todos os direitos reservados'". (Lemos)

Esse controle entretanto, não é absoluto. Em cada uma das camadas existem ainda alguns elementos que se configuram como res commune, isto é, bens de todos, e ao mesmo tempo, bens de ninguém, não sujeitos ao controle específico de ninguém ou de nenhuma entidade. $\mathrm{Na}$ tentativa de organizar essas questões, surgem as licenças criativas.

"Autores e detentores de conteúdos podem não se importam que outras pessoas tenham acesso aos seus trabalhos. Eles podem desejar justamente o contrário: o amplo acesso às suas obras, ou eventualmente, que seus trabalho sejam reinterpretandos, reconstruídos e recriados por outras pessoas."(Lemos)

A primeira grande revolução no que diz respeito às licenças criativas na internet, se deu nos EUA, no ano de 1982. Richard Stallman, um hacker da Universidade de Harvard, criou o conceito de Copyleft, que é o contrario de Copyright, que significa que o conteúdo possui todos os direitos reservados ao autor. Já o Copyleft que pode ser traduzido como "Cópia Permitida".

Stallman, criou um novo modelo da tecnologia da computação e da informação que permitia o software fosse livre, o GNU, que é um sistema operacional aberto, que pode ser instalado, modificado e copiado livremente e sem custos. O preceito dessa inovação é a liberdade. Foi o projeto GNU que deu inicio ao sistema amplamente difundido Linux e também ao conceito de Copyleft. Ele permite a modificação, distribuição e cópia de seus sistemas, desde que estes não sejam reproduzidos para fins comerciais. A obra nasceu como uma obra colaborativa e comunitária, não é estático e não possui o sentido apenas do seu criador. Para isso faz-se necessário resgatar Pierry Lévy, que analisa a atuação do autor no ambiente da cibercultura: 
"O autor é a condição de possibilidade de qualquer horizonte de sentido estável. Mas tornou-se banal dizer que a cibercultura coloca muito em questão a importância e a função do signatário. O engenheiro de mundos não assina uma obra acabada, mas um ambiente por essência inacabado, cabendo aos exploradores construir não apenas o sentido variável, múltiplo, inesperado, mas também a ordem de leitura a as formas sensíveis. Além disso, a metamorfose contínua das obras adjacentes e do meio virtual que sustenta e penetra a obra contribui para destruir um eventual autor de suas prerrogativas de fiador de sentido." (Lévy, 1999:138).

Foi então que, com noções parecidas com a do GNU e visando a liberdade na rede, dos indivíduos de compartilhar conteúdos, nasce em 2001 a organização sem fins lucrativos Creative Commons. Lawrence Lessig, profesor de Direito da Universidade de Harvard,criou junto com amigos, a organização, visando o compartilhamento e o uso da criatividade e do conhecimento através de licenças jurídicas gratuitas, não como autora de conteúdos, mas sim, criando uma forma criativa, universal e padronizada de detentores de conteúdos autorizarem o uso de suas obras.

"As leis sobre direitos autorais determinam que, em regra, todas essas ações precisam de expressa e prévia autorização por parte do autor da obra. Não importa se você é um artista, um professor, um estudante, um pesquisador, um bibliotecário, um político ou um usuário comum. Assim, o uso de uma obra sem a devida autorização é considerado pela legislação como violação aos direitos autorais, salvo algumas exceções." (Creative Commons)

A organização lida com a parte estrutural, mas fica por conta dos autores utilizarem-no de maneira mais adequada para o seu produto, o conceito de compartilhamento. Desta maneira, foram criadas várias licenças $\mathrm{CC}$, elas variem de acordo com a liberação e o uso. Fica sob a responsabilidade do autor fazer uma combinação ou não das licenças que são gratuitas.Todas exigem que o autor citado ou referenciado. Segue quadro explicativo de algumas licenças: 
CC By Está licença permite que a distribuam, remixem, ajustem e aperfeiçoem seu trabalho, até mesmo para fins comerciais, deste que cite o autor. Ė a mais flexivél. Recomendada para máxima utilização e divulgação.

(c) (1) (2)

aperfeiçoem mesmo para fins comerciais, desde que seja dado crédito e que licenças novas criações sob condições idênticas. Esta licença é muitas vezes comparada às licenças "copyleft" de software livre e de código aberto.

(c) $(1) \odot$

CC-By-ND Esta licença permite a redistribuição comercial e não comercial, contanto que seja passada adiante sem alterações e na íntegra, dando reconhecimento ao autor.

(c) (1) (\$)

CC BY-NC Esta licença permite que outras pessoas remixem, ajustem e aperfeiçoem o trabalho de maneira não comercial.

(c) (1) (5) (2)

cc) aperfeiçoem seu trabalho sem fins comerciais, desde que seja dado crédito ao autor e licencie as novas criações sob condições idênticas

(c) (1) $(9$

c) que se faça download de suas obras e as compartilhe com os outros, desde que dêem o crédito ao autor, mas não se alterá-las de qualquer maneira ou usá-las para usá-las.

O Brasil foi o terceiro país a aderir às licenças, ficando atrás de Finlândia e Japão. No Brasil, quem administra a organização Creative Commons desde 2003 é a Fundação Getúlio Vargas, do Rio de Janeiro (FGV/RJ), por meio do Centro de Tecnologia e Sociedade (CTS). O objetivo da FGV é adaptar o Creative Commons aos conceitos jurídicos Brasileiros.

\section{Análises}

Foram analisados os sites dos 26 ministérios brasileiros, das 8 secretarias com status de ministérios, de quatro órgãos organizativos do governo e do site da presidência da república. 
A metodologia escolhida foi a análise quantitativa, por meio da verificação se os portais e sites do governo obtiam ou não o selo Creative Commons.

Aqui abordaremos somente pela a noção quantitativa. Porém, fica evidente a necessidade de analisar a questão por meio de uma abordagem qualitativa, entendendo o porquê de que cada órgão possuir ou não o selo Creative Commons; como foi o processo para que eles que possuem para instituir o selo, entendo os motivos para em alguns casos obter-se todos os direitos reservados, realizando uma analise mais aprofundada da questão.

Dos 39 órgãos analisados (ANEXO I) apenas 7,62\% possuem o selo Creative Commons.Os selos utilizados são o CC-By-Nc; CC-BY- AS e o CC-By-3.0-BR. O último é um selo especifico, adaptado as leis brasileiras, é utilizado pelo Ministério das Comunicações. $58,97 \%$ dos portais e sites não possuem nenhuma menção sobre restrição ou licença de uso de seus conteúdos e informações. Já, 25,64\% possuem restrições de uso de conteúdos, sendo destes $20,51 \%$ denominados todos os direitos e aproximadamente $5,12 \%$ em copyright. Aproximadamente $8 \%$ foram incluídos em exceções, são:

- O portal da Presidência, pois não há nenhuma menção sobre CC, contudo, cita que site é disponibilizado em Softaware Livre.

- O Ministério de Pesca e Aquicultura, que licencia seus conteúdos, mas não em Creative Commons. Com a seguinte frase "O conteúdo deste site, vedado o seu uso comercial, poderá ser reproduzido desde que citada a fonte, excetuados os casos especificados em contrário e os conteúdos dos replicados de outras fontes." (Ministério da Pesca e Aquicultura)

- E por fim, o Ministério da Cultura que licencia seus conteúdos, mas não em CC. É sim com "Licença de Uso: O conteúdo deste site, vedado ao seu uso comercial, poderá ser reproduzido desde que citada a fonte, excetuando os casos especificados em contrário e os conteúdos replicados de outras fontes"(Ministério da Cultura). A seguir, iremos analisar o uso da licença CC no Ministério da Cultura, por haver especificidades importantes.

\section{Ministério da cultura}

As disputas políticas e ideológicas do uso do selo Creative Commons pelo governo brasileiro são um problema recorrente, o melhor exemplo é o caso do Ministério da Cultura (Minc). No ano de 2003, Gilberto Gil - renomado cantor e compositor brasileiro e um dos participantes 
do Tropicalismo, movimento que marcou história na cultura Brasileira - assumia a pasta do referido ministério. Defensor da cultura livre, Gil foi um dos principais defensores do uso da licença Creative Commons no Governo. Em 2007, lançou uma carta que relaciona o CC ao Tropicalismo, onde dizia:

Sempre pensei cultura como uma obra aberta, como um software de código aberto. As trocas com o que é dos outros, a antropofagia cultural constante, fazem parte das vitalidades das culturas, e a possibilidades de trocas livres devem ser preservadas contra qualquer tentativa de imposição (GIL, 2007)

O ministério atuou na construção de políticas públicas de cultura em geral, juntamente com a sociedade, organizações não governamentais e produtores de cultura fazendo um canal direto de diálogo e colaboração. Partindo desta perspectiva, em 2004 o ministro incluiu o selo Creative Commons no Ministério da Cultura e tornou-se parceiro da organização no Brasil, passando a incentivar no governo federal a licença criativa, o software livre e o Copyleft. Ou seja, conceitos de liberdade, colaboração e democratização na rede, tornando o Governo Lula referência no assunto. Em discurso realizado na $5^{\text {a }}$ Conferência da Comunidade dos Países de Língua Portuguesa (CPLP), o presidente Lula falou um pouco sobre o assunto: "Os recursos da moderna tecnologia de comunicações contribuem para a transparência na administração pública. Estamos discutindo maneiras de fortalecer a cidadania e aperfeiçoar as instituições democráticas". (LULA, 2004). No ano de 2008, Gil deixou o ministério da Cultura, que passou a ser gerido pelo sociólogo Juca Ferreira. Dentre as ações do ministério, inclusive o apoio ao Creative Commons, é mantida.

Passados quatro anos, ocorre mais uma mudança no ministério, agora por conta da mudança do governo, que continua sendo administrado pelo mesmo partido, o Partido dos Trabalhos (PT), mas agora por Dilma Rousseff, que assume a presidência do país em 2011. Para a pasta da cultura ela nomeou Ana de Hollanda. Recém empossada no cargo, a ministrada Anna de Hollanda retira o selo creative Commons do site do Ministério da Cultura. Com a alegação de que o ministerio não poderia incentivar a prática de uma organização unitariamente, o selo foi substítuido pela seguinte frase: "Licença de Uso: O conteúdo deste site, vedado ao seu uso comercial, poderá ser reproduzido desde que citada a fonte,excetuando os casos especificados em contrário e os conteúdos replicados de outras" Tirando o caráter de padronização que já estava instituído anteriormente pela licença CC-BySA. 
A ação da ministra é vista como um retrocesso dentro do governo com relação a liberdade na difusão da informação, e como afirma Lemos, ao site Cultura Livre "Após esta alteração no site do Ministério da Cultura não há uma licença clara que autorize o uso do conteúdo que está lá. Qualquer um usando o conteúdo do site enfrenta um grande problema de insegurança jurídica". Isso porque todos os documentos anteriormente licenciados em CC, devem conter a informação que são licenciados.

Do ponto de vista dos ativistas e adeptos do setor, a ação foi considerada como uma clara anunciação de que as políticas públicas de cultura, em geral, implementadas por Gil e continuadas por Ferreira seriam vistas de uma forma diferente para ativistas da liberdade na internet. No portal Trezentos, um movimento da sociedade civil que luta pela democratização da informação na rede, Rodrigo Savazoni aparece com a seguinte informação:

"A opção pela retirada da licença Creative Commons do site do Ministério da Cultura é reflexo de um posicionamento político assumido pela Ministra Ana de Hollanda. Não se trata de medida menor ou ação isolada, e sim é parte de uma estratégia que resultou no estremecimento da relação do Ministério da Cultura com as forças defensoras do compartilhamento do conhecimento e da colaboração cultural" (SAVAZONI, 2011).

\section{Democratização}

As informações que são disponibilizadas virtualmente pelo governo, podem ser consideradas como parte da comunicação pública. Para Duarte (2007, P.03), a comunicação pública é o campo que inclui tudo que diga respeito ao aparato estatal, às ações governamentais. $O$ caráter de protagonismo dos indivíduos de serem também transmissores da comunicação governamental fica comprometido, quando percebe-se que $98 \%$ dos sites e portais do governo, mesmo aqueles que não possuíam nenhuma menção sobre as regras de compartilhamentos, destacavam a Lei de Acesso à Informação, que tem como premissa no Art. $41 \mathrm{da} l \mathrm{ei}^{2}$ "A abrangência nacional de fomento à cultura da transparência na administração pública e conscientização do direito fundamental de acesso à informação;"(LAI, 2011, art.41)

\footnotetext{
${ }^{2}$ LEI № 12.527, DE 18 DE NOVEMBRO DE 2011.
} 
Os portais do governo funcionam como fonte oficial de informações do Estado para a sociedade como um todo. Essas informações em geral, precisam ser compartilhadas - seja para meios de comunicação de massa, ou por qualquer cidadão que queira compartilhar informações- modificadas e redistribuída pois, são informações relevantes a sociedade e muitas vezes precisam ser modificadas para o melhor entendimento dos cidadãos.

"O governo precisa incentivar de diversas formas essa democratização da comunicação, entendo que nela, o individuo é um ator social que também transmite e não pode ser banido de compartilhar, ou ainda, reformular informações ou conteúdos do governo. Mas, para que de fato ocorra a democratização da comunicação é preciso que o governo democratize a sua informação permitindo um espaço dialógico de construção das informações com a sociedade. A democratização da comunicação, Significa possibilidades mais amplas - para as nações, forças políticas, comunidades culturais, entidades econômicas e grupos sociais - de intercambiar informações num plano de igualdade, sem domínio dos elementos mais fracos e sem discriminações. Em outras palavras, implica mudanças de perspectiva."(Murilo Cezar Ramos, 2005, p. 49)

O objetivo do Creative Commons é propor uma forma padronizada e universalizada de permissão para o compartilhamento e a modificação dos conteúdos do governo de maneira democrática. "O CC cumpre um papel de universalização e acesso e democratização da cultura, a comunicação e a informação", é o que diz o site da organização. As licenças fazem com que a informação seja claramente e legalmente disponibilizada para o uso de todos. Ao vermos sites e portais do governo notificando que todas as informações contidas ali possuem direitos reservados, tira-se o direito de usar e distribuir as informações que são de interesse social, impedindo assim um o direito à comunicação. Portanto, cabe ressaltar a importância de entender a comunicação como um direito do cidadão.

"A digitalização da informação e a convergência que ela possibilita de suportes técnicos, de conteúdos e de serviços - da qual a manifestação mais evidente é a (...) Entendemos que tornasse imperativo retomar o debate sobre o direito à comunicação enquanto um novo direito humano fundamental. Um direito social de "quarta geração", aquele, quem sabe, mais adequado para amparar, nas sociedades da informação e da comunicação, nossas inesgotáveis expectativas 
de avanço crescente da democracia da igualdade em todo o mundo."(Ramos, 2005, p. 247)

A Comunicação Pública ocupa-se da viabilização do direito social coletivo e individual ao diálogo, à informação e expressão. Assim, fazer comunicação pública é assumir a perspectiva cidadã na comunicação envolvendo temas de interesse coletivo. (Duarte 2007, P.6). O caráter de protagonismo dos indivíduos de serem também transmissores da comunicação governamental .

\section{Considerações finais}

Ao final de trabalho, tivemos a oportunidade de acompanhar de forma mais atenta, o processo realizado pelo Creative Commons através de suas licenças na mudança do cenário virtual da internet, em busca de uma maior liberdade neste epaço. Pode-se concluir também acerca do papel que este desempenha junto as instituições governamentais, no caso do Brasil em especifico, como tamém seu impacto na sociedade e na vida de cada cidadão exclusivamente. Partindo dessa mesmo ótica, é claro a necessidade dos cidadãos perante o desejo de se manter informado.

A proposta do Creative Commons junto aos governo é justamente, democratizar e facilitar o acesso a esse tipo de informação através do meio virtual, permitindo o seu compartilhamento em prol da utilidade pública. Padronizando mecanismos de liberdade de expressão e de democratização da comunicação e da informação. Contudo não há uma política nacional, que abranja todos os òrgãos de padronização de licenças de conteúdos do Governo Federal.. Talvez num futuro até muito próximo, poderemos acançar o desejável em termos de democratização da informação via internet.

Com relação ao governo brasileiro, um resultado desse avanço a a Lei de acesso a informação, que se apresenta como um primeiro passo muito importante para proporcionar a sociedade um maior acesso a dados governamentais de quaisquer área que antes eram de acesso restrito a entidades e pessoas importantes de dentro do próprio governo. Ela pode ser vista como uma ferramenta na mão do cidadão e como uma iniciativa em prol da transparência no governo, que com tal atitude, tenta demonstra que não há o que esconder que a informação deve estar sempre a serviço de todos, e não o oposto.

Contudo, e não menos importante, todos esses acontecimentos surgem como pequenas ações isoladas que vão ganhando força a medida que são abraçadas pelos membros da 
sociedade. Logo, a constatação que se pode chegar é: para que os processos de garantia dos direitos aconteçam, nesse caso acesso a informação e o direito a comunicação, a colaboração entre sociedade e governo se apresenta como diferencial importantíssimo para se alcançar os objetivos que são traçados.

\section{Bibliografía}

AMADEU, Sérgio. (2007) Comunicação digital, redes virais e espectro aberto.Libero, Recuperado em março, 28, 2013 de http://www.revistas.univerciencia.org/index.php/libero/article/view/3193/3003

AMADEU, Sérgio (2007) O conceito de commons na cibercultura, Santos. Recuperado em março, 28, $2013 \quad$ de http://www.revistas.univerciencia.org/index.php/libero/article/viewFile/5397/4914

CASTELLS, Manuel. A sociedade em rede. São Paulo: Paz e Terra, 1999. v. 1

Discurso Lula 5a Conferência da Comunidade dos Países de Língua Portuguesa (CPLP). Recuperado em abril, 03,2013 de http://www.softwarelivre.gov.br/noticias/presidentelula/

DUARTE, Jorge (Org.). (2007)Comunicação Pública: Estado, Mercado, Sociedade e Interesse Público. São Paulo: Atlas.

FONSECA, André (2006) Copyleft: a utopia da pane no sistema. Revista de Economia Politica delas Tecnologías de la Información y Comunicación www.eptic.com.br, Vol. VIII, n. 2.

Gil, Gilberto Gilberto Gil e a Cultura Livre.(2007) Recuperado em abril, 03,2013 de http://www.nautilos.com.br/artigos/internet/gilberto-gil-e-a-cultura-livre

LEMOS, Ronaldo (2005) Recuperado em março, 20, 2013 de http://bibliotecadigital.fgv.br/dspace/bitstream/handle/10438/2190/Ronaldo\%20Lemos\%2 0-\%20Direito\%20Tecnologia\%20e\%20Cultura.pdf?sequence=1

LEMOS, R \& BRANCO, V. S. (2006) Copyleft, Softaware Livre e Cretaive Commons: A nova feição dos direitos autorais e as obras colaborativas Rio de Janeiro.

LÉVY, Pierre. Cibercultura. São Paulo: Editora 34, 1999

LESSIG, Lawrence. Cultura livre: como a grande mídia usa a tecnologia e a lei para bloquear a cultura e controlar a criatividade. São Paulo: Trama, 2005. 
SAVAZONI, Rodrigo (2011)Ana de Hollanda, o Comando de Caça aos Commonistas e a transição conservadora? Recuperado em abril, 05, 2013 de http://www.brasildefato.com.br/node/5561

RAMOS, M. C. Comunicação, direitos sociais e políticas públicas. In MARQUES DE MELO, J.; SATHLER, L. Direitos à Comunicação na Sociedade da Informação. São Bernardo do Campo, SP: Umesp, 2005

Fundação Getulio Vargas, Recuperado em abril, 07,2013http://portal.fgv.br/

Creative Commons. Recuperado em abril, 07,2013http://creativecommons.org.br/

Sites e portais dos ministérios.Recuperado em abril, 26, 2013 todos os os portais http://www2.planalto.gov.br/presidencia/ministros/ministerios

\section{Anexo I}

\begin{tabular}{|c|c|c|}
\hline Órgão/Ministério/Secretaria & Possui Creative? & Status dos conteúdos \\
\hline 1.Advogacia Geral da União & não. & todos os direitos reservados \\
\hline 2.Banco Central & não & todos os direitos reservados \\
\hline 3.Casa Civil & não informado & - \\
\hline 4.Contraladoria Geral da União & não informado & - \\
\hline 5.Gabinete de segurança institucional & não informado & - \\
\hline 6.Ministério da Agricultura & não informada & - \\
\hline 7.Ministério Ciencia e Tecnologia & não & Copyright $@$ \\
\hline 8.Ministério Cultura & exceção & $\begin{array}{l}\text { O conteúdo deste site, vedado ao seu uso } \\
\text { comercialpoderá ser reproduzido desde que citada a } \\
\text { fonte, } \\
\text { excetuando os casos especificados em contrário e os } \\
\text { conteúdos replicados de outras fontes }\end{array}$ \\
\hline 9.Ministério Defesa & não & Copyright $@$ \\
\hline
\end{tabular}

Facultad de Ciencias de la Información - Universidad de La Laguna

Avenida César Manrique, s/n; Campus de Guajara

38071 La Laguna, Tenerife (Islas Canarias - España) 


\begin{tabular}{|c|c|c|}
\hline 10.Ministério Educação & não & todos os direitos reservados \\
\hline 11.Ministério Fazenda & não informado & - \\
\hline 12.Ministério Integração Nacional & não informado & - \\
\hline 13. Ministério da justiça & não informado & - \\
\hline 14.Ministério Pesca e Aquicultura & exceção & $\begin{array}{l}\text { O conteúdo deste site, vedado o seu uso comercial, } \\
\text { poderá ser reproduzido desde que citada a fonte, } \\
\text { excetuados os casos especificados em contrário e os } \\
\text { conteúdos dos replicados de outras fontes. }\end{array}$ \\
\hline 15.Ministério Previdência Social & não & todos os diretos reservados \\
\hline 16.Ministério saúde & não informado & - \\
\hline 17.Ministério das cidades & não informado & - \\
\hline 18.Ministério comunicações & sim. & $\begin{array}{l}\text { O conteúdo deste sítio pode ser distribuído de acordo } \\
\text { com os termos da licença Creative Commons } \\
\text { Atribuição } 3.0 \text { Brasil (CC BY 3.0) }\end{array}$ \\
\hline 19.Ministério relacoes exteriores & não informado & - \\
\hline 20. Ministério minas e energias & não informado & - \\
\hline 21.Ministério desenvolvimento agrario & $\operatorname{sim}$ & CC-By-NC \\
\hline $\begin{array}{l}\text { 22. Ministério deselvolvimento social } \\
\text { e combate à fome }\end{array}$ & não informado & - \\
\hline $\begin{array}{l}\text { 23.Ministério desenvolvimento, } \\
\text { industria e comercio exterior }\end{array}$ & não informado & - \\
\hline 24.Ministério esporte & não & todos os direitos reservados \\
\hline 25.Ministério meio ambiente & não & todos os direitos reservados \\
\hline $\begin{array}{l}\text { 26.Ministério } \\
\text { orçamento e gestão }\end{array}$ & não informado & - \\
\hline 27.Ministério trabalho e emprego & não & todos os direitos reservados \\
\hline 28.Ministério turismo & não informado & - \\
\hline
\end{tabular}




\begin{tabular}{|c|c|c|}
\hline 29.Ministério transportes & não informado & - \\
\hline $\begin{array}{l}\text { 30.Secretaria de assuntos de } \\
\text { assuntos estratégicos da PR }\end{array}$ & $\operatorname{sim}$ & CC- By- Sa \\
\hline 31.Secretaria de aviação civil da PR & não informado & - \\
\hline 33.Secretaria de Direitos Humanos & não informado & - \\
\hline $\begin{array}{l}\text { 34.Secretaria de politicas de } \\
\text { promoção da igualdade racial }\end{array}$ & não informado & - \\
\hline $\begin{array}{l}\text { 37.Secretaria de relações } \\
\text { institucionais da PR }\end{array}$ & não informado & - \\
\hline 38.Secretaria- Geral da PR & não informado & - \\
\hline
\end{tabular}

\section{Forma de citar este artículo en bibliografías}

DA COSTA, Gabriella (2013): "Creative commons no governo federal brasileiro: Comunicação e democratização" en Revista PANGEA, 4, páginas 174 a 189. Red Académica Iberoamericana de Comunicación. Recuperado el _ de __ de 2 ___ de: http://www.revistapangea.org 